\title{
A Study on Management of Paediatric Empyema Cases: Clinical Study
}

\author{
Sudhakar Hegade ${ }^{1}$, Sandeep Biradar ${ }^{2}$ \\ ${ }^{1}$ Assistant Professor, Department of Pediatrics, VIMS, Ballari, Karnataka, ${ }^{2}$ Pediatrician, General Hospital, Basavakalyana, Karnataka.
}

\section{Abstract}

Background: Empyema thoracis is a condition in which pus and fluid from infected tissue collects in the pleural cavity. Childhood empyema is an important complication of bacterial pneumonia. The incidence of empyema is increasing worldwide. Despite being recognized since the ancient times, the appropriate management of paediatric empyema thoracis remains controversial. Subjects and Methods: 50 suspected cases of empyema after admission had a detailed history taking as per the proforma, with emphasis on duration of symptoms, previous medication, contact history of tuberculosis and course of illness before admission. Result: In the present study, 21/50(42\%) were managed with ICD and antibiotics. Another 21 cases (42\%) were managed by ICD with fibrinolytics. Eight cases required thoracostomy and decortication due to poor lung expansion with persisting fever and developed multiple loculations after initial mode of treatment. Amount of pus drained was $700-1000$ $\mathrm{ml}$. The time taken for fever to subside ranged from 4-12 days. Conclusion: Emphasis should be laid on minimizing the duration of hospital stay to bring down expenditure, psychological stress and more importantly nosocomial infections due to multidrug resistant organisms.

Keywords: Empyema Management,Paediatric empyema cases, Clinical study.

Corresponding Author: Dr. Sudhakar Hegade, Assistant Professor, Department of Pediatrics, VIMS, Ballari, Karnataka.

Received: September 2019

Accepted: September 2019

\section{Introduction}

The clinical condition of empyema has been recognized since the days of Hippocrates. Suppurative or pyogenic infection of pleural space is Empyema thoracis. Empyema is never a primary disease, often it is difficult to arrive at primary focus of infection, though pleural cavity is the root of pus, respiratory and cardiovascular systems are severly affected.

Empyema thoracis is still a common entity in developing countries along with high incidence of pneumonia because of multiple factors. Empyemas are a significant cause of morbidity but, fortunately, not mortality in children and at times can be a therapeutic challenge. Part of the problem has been the lack of evidence from paediatric trials, and it is inappropriate simply to extrapolate adult data to children. There are differences between adult and paediatric pleural infections. The principal one is that, since it is rare for children to have an underlying lung disease, the final outcome is almost always excellent. Furthermore, adult empyema carries a $20 \%$ mortality rate which is related to comorbidity (for example, malignancy, immunodeficiency, prolonged hospital stay and nosocomially acquired infection). ${ }^{[1]}$

Incidence of empyema was $0.8 \%$ of total pediatric admissions. 2 Effusions occur in atleast $40 \%$ of bacterial pneumonias, with upto $60 \%$ of effusions resulting in the formation of empyema in all age groups. Recent studies have noted an increase in the incidence of empyemas in children. ${ }^{[2]}$

In developed countries, the microbiological profile has changed over the past five decades with increasing incidence of penicillin resistant streptococcus pneumoniae and methicillin resistant staphylococcus. However, the scenario is very different in developing countries where empyema is associated with significant morbidity and consumption of scarce hospital resources. ${ }^{[3]}$

Optimal management in children is controversial, especially the duration of parenteral antibiotics and the role of surgery. Current treatment of empyema in children is highly variable due to in part both provider experiences and a wide spectrum of clinical presentations. Newer therapies such as fibrinolysis3 and Video Assisted Thoracoscopic Surgery8 have made the issue even more complex. ${ }^{[4]}$

Chronic empyema is the outcome of improper management in the acute stage. The disability produced by persistence of chronically infected pleural space is very grave. With this scenario in mind, we decided to conduct this study in our epidemiological setup to define the clinical course, bacteriological profile, radiological features, various modalities of treatment and their outcome. This would guide us to use appropriate antibiotics and management strategies. ${ }^{[5,6]}$

\section{Subjects and Methods}

50 suspected cases of empyema after admission had a 
detailed history taking as per the proforma, with emphasis on duration of symptoms, previous medication, contact history of tuberculosis and course of illness before admission.

Patients were examined thoroughly for vital signs, nutritional status and respiratory signs of empyema thoracis. Suspected cases were confirmed after chest $\mathrm{x}$-ray and ultrasonography. In all clinically suspected cases diagnostic thoracocentesis was performed under local anesthesia with $2 \%$ xylocaine using sterile disposable syringe (needle size$18 \mathrm{G}$ ), which was introduced through 5th intercostal space in mid axillary line or area of maximal dullness, appearance of pus clinches the diagnosis. About $5 \mathrm{ml}$ of pus was drawn in each case and sent for cytology, ADA, LDH, glucose, protein, microbiology for gram stain, AFB stain and culture sensitivity.

Routine investigations like Haemoglobin, total and differential count, ESR were done in all cases. Coagulation profile was done in cases of Intrapleural fibrinolytic treatment.

Those in severe distress underwent immediate ICD and those who were not were evaluated by USG and managed accordingly. Those diagnosed to have non loculated empyema on USG underwent ICD. Intercostal drainage procedure was done with all aseptic precautions with prior consent taken from parents. ICD tube sizes were selected based on the age of the child and viscosity of the fluid and inserted in 5th intercostal space in mid axillary line, outer end of the tube was connected to an under water seal kept in sterile condition. Initially intravenous antibiotics like Amoxicillin-clavulanic acid started in the dose of 100 $\mathrm{mg} / \mathrm{kg} /$ day in three divided doses and Amikacin in the dose of $15-20 \mathrm{mg} / \mathrm{kg} /$ day in two divided doses were started. Appropriate antibiotics were added according to culture sensitivity reports.

Chest $\mathrm{x}$ ray was immediately taken after ICD insertion to confirm the exact position of the tube, as well as to document lung expansion and residual collection subsequently. Daily bedside examination was done to check for vital signs, air entry and the patency of the ICD tube and monitoring of drain output . Whenever blockage was suspected, intercostal tube was readjusted. For those with persistent symptoms and no signs of improvement, repeat ultrasound was done to look for any loculations following tube thoracostomy. All patients were advised on good nutritional intake. Chest physiotherapy was started at the earliest. All of them were encouraged to blow balloons or use incentive spirometry for good lung expansion. ICD was removed when the drainage was less than $50 \mathrm{ml} /$ day with radiological and clinical improvement.

All the patients with persistent clinical symptoms, incomplete lung expansion on ICD and antibiotics, loculations seen on ultrasonography at admission or developed during the course of hospital stay were subjected to intra-pleural fibrinolytic instillation.
Results

Table 1: Anaemia Incidence

\begin{tabular}{|l|l|l|}
\hline Haemoglobin & No. of Patients $(\mathrm{n}=50)$ & $\%$ \\
\hline$<7$ & 11 & 22 \\
\hline $7-10$ & 28 & 56 \\
\hline$>10$ & 11 & 22 \\
\hline Total & 50 & 100.0 \\
\hline
\end{tabular}

39 out of 50 patients $(78 \%)$ were anemic. Of which $11 / 60$ (22\%) had $\mathrm{Hb}$ less than $7 \mathrm{gm} / \mathrm{dl}$.

Table 2: Total Leukocyte Count in empyema patients

\begin{tabular}{|l|l|l|}
\hline Total Count & No. of Patients $(\mathbf{n}=\mathbf{5 0})$ & \% \\
\hline$<4000$ & 2 & 4 \\
\hline $4000-11000$ & 14 & 28 \\
\hline$>11000$ & 34 & 68 \\
\hline Total & 50 & 100.0 \\
\hline
\end{tabular}

Leucocytosis was found in $34 / 50$ cases (68\%). Leucopenia were seen in $2 / 50$ cases $(4 \%)$. Though leucocytosis was seen in only $34 / 50(68 \%)$, neutrophilia was seen in $80 \%$ of the cases.

\begin{tabular}{|l|l|l|}
\hline Table 3: Radiological pattern of empyema in children \\
\hline Radiological Pattern & No. of Patients $(\mathbf{n}=50)$ & $\%$ \\
\hline CXR & & \\
\hline Hydrothorax & 44 & 88 \\
\hline Hydropneumothorax & 6 & 12 \\
\hline Usg Thorax & & \\
\hline Loculations & 23 & 46 \\
\hline No Loculations & 27 & 54 \\
\hline Total & 50 & 100.0 \\
\hline
\end{tabular}

44/50 (88\%) had hydrothorax on Chest X-ray and 6/50 (12\%) cases had hydropneumothorax. $8 / 50(16 \%)$ had mild empyema, 20/50 (40\%) had medium and 22/50 (44\%) had large empyema. Mild- Some costophrenic blunting, Medium- Opacity involving half of hemithorax, LargeOpacity over more than half of hemithorax.

$23 / 50(46 \%)$ of the cases had loculated empyema and $27 / 50$ (54\%) had non-loculated empyema.

Table 4: Macroscopy

\begin{tabular}{|l|l|l|}
\hline Pleural Fluid Macroscopy & No. of Patients $(\mathbf{n = 5 0})$ & \% \\
\hline Pus & 40 & 80 \\
\hline Seropurulent & 10 & 20 \\
\hline Total & 50 & 100.0 \\
\hline
\end{tabular}

$40 / 50(80 \%)$ had pus on diagnostic thoracocentesis and $10 / 50(20 \%)$ had seropurulent effusion.

Table 5: Pleural Fluid - Biochemical parameters
\begin{tabular}{|l|l|l|l|}
\hline $\begin{array}{l}\text { Pleural fluid } \\
\text { biochemical parameters }\end{array}$ & Criteria & $\begin{array}{l}\text { No. of Patients } \\
(\mathrm{n}=50)\end{array}$ & $\%$ \\
\hline Total Count & $<11000$ & 23 & 46 \\
\hline & $>11000$ & 27 & 54 \\
\hline Glucose & $<40$ & 37 & 74 \\
\hline & $>40$ & 13 & 26 \\
\hline Protein & $<3$ & 46 & 92 \\
\hline & $>3$ & 4 & 8 \\
\hline LDH & $<1000$ & 6 & 12 \\
\hline
\end{tabular}




\begin{tabular}{|l|l|l|l|}
\hline & $>1000$ & 44 & 88 \\
\hline ADA & $<60$ & 26 & 52 \\
\hline & $>60$ & 24 & 48 \\
\hline
\end{tabular}

$37 / 50(74 \%)$ had glucose value $<40 \mathrm{mg} / \mathrm{Dl} .46 / 50(92 \%)$ had protein value more than $3 \mathrm{gm} / \mathrm{dl}$. 44/50 (88\%) had LDH $>1000$ IU/L. 24/50(48\%) had ADA >60. Pleural fluid cell count was more than 11000 cells in $27 / 50$ (54\%) with polymorphonuclear predominance in all.

\begin{tabular}{|c|c|c|}
\hline Treatment & No. of Patients & $\%$ \\
\hline ICD & 21 & 42 \\
\hline ICD with Fibrinolytics & 21 & 42 \\
\hline Open Decortication & 8 & 16 \\
\hline Total & 50 & 100.0 \\
\hline
\end{tabular}

Results of comparative variables of main two treatment groups (ie ICD Vs ICD with fibrinolytics).

Table 7: Duration of hospital stay - mean and standard
deviation
\begin{tabular}{|l|l|l|l|l|}
\hline $\begin{array}{l}\text { Treatment } \\
\text { group }\end{array}$ & $\begin{array}{l}\text { No. of } \\
\text { Patients }\end{array}$ & $\begin{array}{l}\text { Mean } \\
\text { no.of } \\
\text { days }\end{array}$ & $\begin{array}{l}\text { Standard } \\
\text { deviation }\end{array}$ & $\begin{array}{l}\text { Std. } \\
\text { Error } \\
\text { Mean }\end{array}$ \\
\hline ICD & 27 & 17.3 & 4.772 & 0.909 \\
\hline $\begin{array}{l}\text { ICD with } \\
\text { fibrinolytics }\end{array}$ & 23 & 11.6 & 4.979 & 1.038 \\
\hline
\end{tabular}

Table 8: Duration of hospital stay - $t$ test for equality of means

\begin{tabular}{|l|l|l|l|l|}
\hline & \multicolumn{4}{|c|}{ t-test for Equality of Means } \\
\hline $\begin{array}{l}\text { Duration of } \\
\text { hospital stay }\end{array}$ & $\mathrm{t}$ & Df & Significance(2 tailed) & $\begin{array}{l}\text { Mean } \\
\text { Difference }\end{array}$ \\
\cline { 2 - 5 } & 4.14 & 48 & 0.00014 & 5.6876 \\
\hline
\end{tabular}

The mean duration of hospital stay in ICD group was 17.3 days whereas in ICD with fibrinolytics group it was only 11.6 days, which was statistically significant $(\mathrm{p}<0.05)$.

Table 9: Duration of tube insitu - mean and standard deviation

\begin{tabular}{|l|l|l|l|l|}
\hline $\begin{array}{l}\text { Treatment } \\
\text { group }\end{array}$ & $\begin{array}{l}\text { No. of } \\
\text { Patients }\end{array}$ & $\begin{array}{l}\text { Mean } \\
\text { no.of } \\
\text { days }\end{array}$ & $\begin{array}{l}\text { Standard } \\
\text { deviation }\end{array}$ & $\begin{array}{l}\text { Std } \\
\text { Error } \\
\text { Mean }\end{array}$ \\
\hline ICD & 27 & 12.8 & 3.154 & 0.607 \\
\hline $\begin{array}{l}\text { ICD with } \\
\text { fibrinolytics }\end{array}$ & 23 & 8.8 & 3.284 & 0.685 \\
\hline
\end{tabular}

Table 10: Duration of antibiotic treatment - mean and standard deviation

\begin{tabular}{|l|l|l|l|l|}
\hline $\begin{array}{l}\text { Treatment } \\
\text { group }\end{array}$ & $\begin{array}{l}\text { No. of } \\
\text { Patients }\end{array}$ & $\begin{array}{l}\text { Mean } \\
\text { no.of } \\
\text { days }\end{array}$ & $\begin{array}{l}\text { Standard } \\
\text { deviation }\end{array}$ & $\begin{array}{l}\text { Std } \\
\text { Error } \\
\text { Mean }\end{array}$ \\
\hline ICD & 27 & 15.6 & 4.019 & 0.773 \\
\hline $\begin{array}{l}\text { ICD with } \\
\text { fibrinolytics }\end{array}$ & 23 & 10.8 & 3.737 & 0.779 \\
\hline
\end{tabular}

Table 11: Duration of antibiotic treatment $-t$ test for equality of means

\begin{tabular}{|l|l|l|l|l|}
\hline & \multicolumn{4}{|l|}{ t-test for Equality of Means } \\
\hline $\begin{array}{l}\text { Duration of } \\
\text { antibiotic } \\
\text { treatment }\end{array}$ & $\mathrm{T}$ & $\mathrm{Df}$ & $\begin{array}{l}\text { Significance(2 } \\
\text { tailed) }\end{array}$ & $\begin{array}{l}\text { Mean } \\
\text { Difference }\end{array}$ \\
\cline { 2 - 5 } & 4.38 & 48 & 0.0001 & 4.8406 \\
\hline
\end{tabular}

The mean duration of antibiotic treatment in ICD group was 15.6 days whereas in ICD with fibrinolytics group it was only 10.8 days, which was statistically significant $(\mathrm{p}<0.05)$.

Table 12: Failure rate - cross tabulation

\begin{tabular}{|l|l|l|l|l|}
\hline & & ICD & ICD with fibrinolytics & Total \\
\hline Failure & No & $21(77.8)$ & $21(91.4)$ & $42(84 \%)$ \\
\hline & Yes & $6(22.2 \%)$ & $2(8.6 \%)$ & $8 \quad(16 \%)$ \\
\hline
\end{tabular}

Table 13: Incidence of complications in childhood empyema

\begin{tabular}{|l|l|l|}
\hline Complications & No. of Patients & \% \\
\hline No complications & 31 & 62 \\
\hline Complications & 19 & 38 \\
\hline Subcutaneous emphysema & 9 & 18 \\
\hline Tube Blockage & 7 & 14 \\
\hline Blood loss & 1 & 2 \\
\hline Air Leak & 2 & 4 \\
\hline
\end{tabular}

Incidence of complications $\quad 9 / 19 \quad(18 \%)$ had subcutaneous emphysema, $7 / 19$ cases(14\%) had Blockage of tube and 2 cases (4\%) had air leak.

Table 14: Follow-up

\begin{tabular}{|l|l|l|}
\hline Outcome & No. of Patients $(\mathbf{n}=\mathbf{5 0})$ & \% \\
\hline Good Lung Expansion & 48 & 96 \\
\hline Collapse & 2 & 4 \\
\hline Pleural Thickening & 0 & 0 \\
\hline Total & 50 & 100.0 \\
\hline
\end{tabular}

48/50 (96\%) had good lung expansion on follow-up. Two had persistent collapse who improved further on physiotherapy.

\section{Discussion}

Grossly purulent fluid was seen in 40/50(80\%) of the cases and 10/50(20\%) had seropurulent effusion.

The British Thoracic Society Guidelines (2005) opine that there is no data to suggest that biochemical analysis has shown to be of any value in the practical management of children with empyema. This is probably because, unlike in adults, most pleural effusions in children are parapneumonic effusions. ${ }^{[7]}$

Microbes can be seen on Gram stain but empyema fluid can be sterile in culture. In some cases with frank pus, organisms are neither seen on Gram stain nor grown in culture.

In the present study $24 / 50(48 \%)$ of the cases had positive Grams stain but and 23/50(46\%) of the patients had culture positivity and in the remaining $27(54 \%)$ patients no organisms was isolated. The commonest organism isolated was coagulase positive Staphylococcus aureus, which was seen in $9(18 \%)$ of the patients, Streptococcus pneumoniae 6(12\%), Klebsiella and Citrobacter sps in 6(12\%) patients with polymicrobial variety in one of them and pseudomonas aeuroginosa in $2(4 \%)$ cases.

This high percentage of culture negativity is probably due to the prior treatment with antibiotics. 


\section{Hegade \& Biradar; A Study an Management of Paediatric Empyema Cases: Clinical Study}

The reported rate of identifying an infectious organism from pleural fluid varies markedly, from $8 \%$ to $76 \%$. The commonest organism isolated is Staphylococcus aureus which is similar to other studies. ${ }^{[8]}$

If one goes through the investigations in a case of empyema thoracis, it is uncommon to find a big pile of X-rays, sometimes the number of $\mathrm{X}$-rays equal the number of days of hospital stay. The amount of radiation exposure in these patients is a matter of concern.

In the present study X-ray postero-anterior and lateral view were done at the time of admission, next X-ray was taken to know the tube position and the degree of lung expansion. Xray chest was done to see lung expansion during follow up visits.Ultrasonography was done in all 50/50(100\%) of the cases. 23/50(46\%) had loculations and 27(54\%) were nonloculated. A study done by Kearney SE et al ${ }^{[9]}$ (1999) reported 7/36 (19\%) pleural collections were anechoic or non-loculated, 5/36 (14\%) were hyperechoic without septae and 24/36 (67\%) were hyperechoic with septae/ multiple loculi.

The appearances of empyema on ultrasound probably represent different stages of the disease process. Anechoic or hypo-echoic, non-septated fluid precedes hyperechoic fluid and later on septations or loculations develop. This may correlate with progression of empyema from the exudative to fibrinopurulent stage when increasing fibrin deposition causes formation of septations and loculations in the pleural fluid and a rind or peel on the pleural surface. Septations, loculations and thickness of the pleural rind are easy to assess on ultrasound.

The study by Shankar et al ${ }^{[10]}$ (2000) included children and indicated that percutaneous drainage of empyema without using fibrinolytic agents had the best chance of success when the fluid was anechoic and was least likely to succeed when the fluid was complex and septated. In such conditions fibrinolytic agents obviates the need for surgery and caused good lung expansion in follow up X-ray. Sonography is noninvasive, gives no radiation, is easily available and is economical.

Computed tomography was done in $8 / 50(16 \%)$ of the cases to study the details of the pleural and the underlying pulmonary pathology and to determine the time for surgical intervention. $6 / 20(85 \%)$ of them had multiloculated empyema, 2/40(5\%) had underlying organizing thick peel, who proceeded for decortication. A study done by Gun F et al (2007) reported these abnormal CT findings: pleural thickening in $44 / 79(55.6 \%)$, uni or multiloculated empyema in $20 / 79(25.3 \%)$, lung abscess in $12 / 79(15.2 \%)$, and finally pneumatocele in $3 / 79(3.8 \%)$ patients.

A review of literature revealed that CT scans more adequately evaluated lung collapse, atelectasis and the extent of the pleural disease than the conventional chest radiograph.

Despite being recognized since the ancient times, the appropriate management of paediatric empyema thoracis remains controversial. It may be postulated that the most appropriate therapy depends on the stage of the disease at presentation. The literature provides many options including antibiotics alone or in combination with repeated thoracocentesis, closed intercostal tube drainage, fibrinolytics agents like streptokinase or deoxyribonuclease, video-assisted thoracoscopy, mini thoracotomy or formal thoracotomy and decortication. ${ }^{[11]}$

In the present study, 21/50(42\%) were managed with ICD and antibiotics. Another 21 cases (42\%) were managed by ICD with fibrinolytics. Eight cases required thoracostomy and decortication due to poor lung expansion with persisting fever and developed multiple loculations after initial mode of treatment. Amount of pus drained was 700- $1000 \mathrm{ml}$. The time taken for fever to subside ranged from 4-12 days.

Progression of the empyema with the development of fibrinous adhesions and loculations makes simple drainage difficult if not impossible. Chest tube drainage and intravenous antibiotic therapy might be adequate for stage 1 empyema. However, this approach is rarely effective in patients with stage 2 or 3 disease. Although there might be clinical improvement with drainage of the pleural space and antibiotic therapy, re-expansion of the entrapped lung is unlikely to occur in a significant number of cases, and this ultimately leads to use of surgical interventions.

Recognizing the limitations to this approach, some researchers have advocated the use of intrapleural fibrinolytic agents as a form of chemical debridement to enhance pleural drainage and to disrupt loculations.

We practised the same with the changing trend towards use of ICD with fibrinolytics with the aim of reducing the length of hospital stay and the number of ICD days. There were many past series showing increased failure rates of tube thoracostomy without the usage of fibrinolytics when the patients were referred late in fibrinopurulent stage.

All children were started on antibiotics soon after admission, initially with an antibiotic which covers both gram positive and gram negative organisms and changing later based on the culture sensitivity report. We started AmoxicillinClavulanic acid (100 mg/kg/day in three divided doses) and an aminoglycoside (15-20 mg/kg/day in two divided doses). All cases with staphylococcal empyema responded to Vancomycin(40 mg/kg/day in 4 divided doses). None of the cases were resistant to Vancomycin. Streptococcal empyema responded to Amoxicillin-Clavulanic acid in our study. Duration of antibiotic ranged from 12-20 days depending on clinical condition and antibiotic susceptibility.

Information on optimal duration of parenteral antibiotic therapy is lacking. In a retrospective comparative audit, a shift to oral therapy once patients become afebrile, respiratory distress subsided, and significant loculations were ruled out usually after 7-14 days has reduced the hospital stay compared to prolonged parenteral therapy (17.2 \pm 7.2 vs. $23.2 \pm 7.4$ days, $\mathrm{p}<0.01)$ without compromising final clinical outcome. Oral antibiotics were continued to 
complete a therapy of 2-3 weeks. ${ }^{[12]}$

Eight cases $(16 \%)$ required open thoracotomy and decortication as they had thick multiple sepatations and organising peel on CT scans after giving the initial mode of treatment.In a study done by Cohen et $\mathrm{al}^{[13]}$ (2003), compared with the Tube thoracostomy group, the Fibrinolytic group patients had a significantly shorter duration of intravenous antibiotic therapy (18.2 vs. 7.6 days, $p<.001$ ), chest tubes in situ (10.2 vs. 4.0 days, $p<.001)$, and hospital stay (15.4 vs. 7.4 days, $p<.001$ ).

Compared to the previous studies present study shows high incidence of surgical intervention. This may be because of multiloculated empyema. This in turn is due to late presentation, delayed referral, incorrect use of antibiotics which may be inappropriate drugs or inadequate dosages. This results in partial suppression of pathology leading to protracted and chronic illness. Perhaps these are the children who seem to eventually need surgical extirpation of the peel. The other reasons for increase in the rate of the surgery may be the virulence of the organism and host defence factors.

The optimal treatment of Empyema thoracis especially in the fibrinopurulent phase remains controversial so as to whether to go for ICD alone or ICD with fibrinolytics.

A detailed review of literature was done on this which revealed Intrapleural instillation of streptokinase as a superior primary treatment in few studies but not usually routinely practiced. Despite the reported efficacy of different modalities in the treatment of empyema thoracis, an orderly approach to the empyema patient is unclear and cannot be easily established without prospective randomized trials enrolling equivalent patient groups. As majority of patients in the study presented in fibrinopurulent stage, we could only compare ICD and ICD with fibrinolytics. This small study represents a prospective trial to randomize equivalent groups of empyema patients in the fibrinopurulent stage into two above told treatment groups.

Out of the 27 patients in the ICD group 21 had successful treatment afterthe primary intervention i.e. ICD. The remaining 6 had to undergo a second intervention in the form of Thoracotomy. Whereas in the ICD with fibrinolytic group 21 patients out of 23 had success with primary intervention and only 2 patients needed thoracotomy as the second intervention thus the failure rate was $8 \%$ which is far less than that of the ICD group which was $23 \%$. This is the most important issue in this study. The high success rate in Fibrinolytic group attributes to break the loculi and septations and the advantage of clearing the pleural adhesions and giving the best chance of drainage of the collection in the pleural cavity which is not possible in the ICD group. The study done by Nie $\mathrm{W}$ et $\mathrm{al}^{[10]}$ also reported higher significant success rate with Fibrinolytic treatment (91\%) versus the ICD group $66 \%$.

All 50 patients were followed up after the discharge at 1 and 3 months. All of them were evaluated clinically and radiographically. Most of the patients 48/50(96\%) were asymptomatic and had good lung expansion. $2 / 50(4 \%)$ had persistent collapse. All the decorticated patients had normal lung functions.

A study done by Baranwal et al ${ }^{[14]}$ (2003) reported on follow up that, all children were doing well. None had clinically significant restrictive disease.

\section{Conclusion}

Management of primary empyema continues to be controversial in terms of duration of antibiotic therapy and the indications for and timing of surgery. There is a need for randomised controlled trials for strict guidelines on the management of empyema. In stage I empyema with no loculations, antibiotics with ICD would suffice. But in stage II empyema there is a changing trend towards Intrapleural instillation of fibrinolytics in a tertiary care hospital. Intrapleural instillation of Streptokinase provides an effective procedure that combines characterization of the pleural space fluid, cessation of the progression of the parapneumonic process, removes the infected pleural material, allows for maximal lung expansion and function, all with reduced pain and morbidity to the patient and a shortened duration of hospital stay and ICD insitu. Complicated and Stage III empyemas however will require Thoracotomy and decortication.

\section{References}

1. Rocha de la A. Empyema thoracis. Surg Gynecol Obstet 1982; 155 : 839-45.

2. Gün F, Salman T, Abbasoglu L et al. Early Decortication in Childhood Empyema Thoracis. Acta Chir belg 2007; 107: 225-227.

3. Karmarkar DP and Walimbe AV. Empyema thoracis in children Indian Pediatr 2001;15(3):245-48.

4. Chonmaitree T, Powell KR. Parapneumonic pleural effusion and empyema in children. Review of a 19 year experience. 1962-1980. Clin Pediatr 1983; 22: 414-419.

5. Behrman RE, Kliegman RM, Jenson HB. Purulent pleurisy (empyema). Nelson textbook of pediatrics; 18th edition, Philadelphia, Elsevier, 2008 , pp 1834-35.

6. Seaton A, Seaton D, Leitch AG. Empyema. Crofton and Douglas's Respiratory Diseases; 5th edition, UK, Blackwell sciences, 2000, pp 450.

7. Balfour-Lynn IM, Abrahamson E, Cohen G et al. BTS guidelines for the management of pleural infection in children. Thorax [Suppl] 2005; 60:1-21.

8. Givan DC, Eigen H. Common pleural effusions in children. Clin Chest Med: 1998; 19: 363-371.

9. Bose K et al. Analysis of outcome of Intrapleural Streptokinase in pediatric empyema thoracis even in advanced stages: A prospective study. Iran journal of paediatrics;August 2015

10. Nie $\mathrm{W}$ et al. Efficacy of Intrapleural instillation of fibrinolytics for treating pleural empyema and para-pneumonic effusions: A meta analysis of randomized control trials.

11. Wait MA, Sharma S, Hohn J, Nogare AD. A Randomized Trial of Empyema Therapy. Chest 1997;111:1548-51.

12. Jaffe' A, Cohen G. Thoracic empyema. Arch Dis Child 2003; 88: 839-841.

13. Cohen G, Hjortdal V, Ricci M et al. Primary thoracoscopic treatment of empyema in children. J Thorac Cardiovasc Surg 2003;125: 79-84. 
14. Baranwal AK, Singh M, Marwaha RK. Empyema thoracis: a 10-year comparative review of hospitalised children from south Asia. Arch Dis Child 2003; 88: 1009-1014.

Copyright: () the author(s), 2019. It is an open-access article distributed under the terms of the Creative Commons Attribution License (CC BY 4.0), which permits authors to retain ownership of the copyright for their content, and allow anyone to download, reuse, reprint, modify, distribute and/or copy the content as long as the original authors and source are cited.

How to cite this article: Hegade S, Biradar S. A Study on Management of Paediatric Empyema Cases: Clinical Study. Asian J. Clin.Pediatr.Neonatol.2019;7(3):54-59.

DOI: dx.doi.org/10.21276/ajcpn.2019.7.3.14

Source of Support: Nil, Conflict of Interest: None declared. 